\title{
BMP controls nitric oxide-mediated regulation of cell numbers in the developing neural tube
}

\author{
A Traister ${ }^{1,4}$, S Abashidze ${ }^{1,4}, V_{\text {Gold }}{ }^{1}, \mathrm{R}$ Yairi $^{1}$, E Michael $^{1}$, \\ N Plachta ${ }^{1,5}$, I McKinnell $^{2}$, K Patel $^{2}$, A Fainsod ${ }^{3}$ and M Weil ${ }^{\star, 1}$ \\ 1 Department of Cell Research and Immunology, The George S Wise Faculty of \\ Life Sciences, Tel Aviv University, Ramat Aviv, Tel Aviv 69978, Israel \\ ${ }^{2}$ Veterinary Basic Sciences, Royal Veterinary College, Royal College Street, \\ London NW1 OUT, UK \\ 3 Deptartment of Cellular Biochemistry and Human Genetics, The Hebrew \\ University-Hadassah Medical School, Jerusalem 91120, Israel \\ ${ }^{4}$ Both these authors contributed equally to this work \\ 5 Present address: Biozentrum, University of Basel, Klingelbergstrasse 50, \\ $\mathrm{CH}-4056$ Basel, Switzerland \\ * Corresponding author: M Weil, Department of Cell Research and Immunology, \\ The George S Wise Faculty of Life Sciences, Tel Aviv University, Ramat Aviv, \\ Tel Aviv 69978, Israel. Tel: + 972-3-6406981; Fax: + 972-3-6422046; \\ E-mail: miguelw@tauex.tau.ac.il
}

Received 13.11.03; revised 19.12.03; accepted 23.12.03; published online 2.4.04 Edited by Dr G Melino

\section{Abstract \\ Balanced cell proliferation and cell death determines neural precursor cell numbers in early stages of neural tube (NT) development. We have previously shown that nitric oxide (NO) regulates cell numbers locally in the NT of eight to 12 somite embryos. Here, we demonstrate that bone morphogenetic protein-4 (BMP-4), which is expressed in the ectoderm and dorsal NT at these developmental stages, induces programmed cell death (PCD) and promotes entry into the S-phase, via nitric oxide synthase (NOS) activity. These effects can be reversed by BMP-4 antagonists, such as follistatin and noggin, or by specific NOS inhibitors, resulting in low NO levels that facilitate mitosis and reduce PCD. Ectopic BMP-4 induction of PCD is restricted to the dorsal NT, whereas promotion of the S-phase is evenly observed across the dorsal-ventral (D-V) axis. Prolonged exposure to either BMP-4 or NOS inhibitors, which results in high or low NO levels, respectively, causes NT defects. The results presented here throw new light on the BMP signaling pathway. The local presence of BMP-4 helps to regulate cell numbers in the developing NT by a NO-mediated pathway, which is essential for normal NT formation. \\ Cell Death and Differentiation (2004) 11, 832-841. \\ doi:10.1038/sj.cdd.4401404 \\ Published online 2 April 2004}

Keywords: BMP; nitric oxide; neural tube; cell numbers; apoptosis; cell cycle; neural tube defects; Wnt signaling

Abbreviations: BMP, bone morphogenetic protein; BrdU, bromodeoxyuridine; DAF-2DA, 4,5-diaminofluorescein diacetate; LNMMA, $N^{G}$-methyl-L-arginine; NO, nitric oxide; NOS, nitric oxide synthase; NT, neural tube; PCD, programmed cell death; PI, propidium iodide; SNAP, $S$-nitroso- $N$-acetyl-penicillamine

\section{Introduction}

Cell numbers in multicellular organisms are determined by the balance between cell death and cell proliferation. However, the molecular mechanism of the spatiotemporal control of cell numbers remains poorly understood. The importance of programmed cell death $(P C D)$ as a fundamental homeostatic mechanism during normal development is well established. ${ }^{1}$ In many cases, a combination of PCD-activating and preventing factors determines the survival and death of specific cells. ${ }^{2-4}$ However, it is yet unclear as to how extracellular signals interact with intracellular signaling pathways to modulate the local balance between cell death and cell proliferation of most cell types. This important biological question should be addressed to allow an understanding of how organized tissues and organs form in the developing embryo.

Specific inhibitors of PCD block neural tube (NT) closure in explanted chicken embryos, suggesting that $P C D$ is required for this crucial developmental process. ${ }^{5}$ The obvious explanation for this phenotype was that blocking PCD at the time of NT closure affects cell numbers. We have recently reported that NO, a short-lived and short distance-acting mediator molecule, is endogenously produced in the neuroepithelium of eight to 12 somite chicken embryos, and plays a role in the regulation of cell cycle progression ${ }^{6}$ and cell numbers in vivo. ${ }^{7}$ High NO levels on the basal side promote entry into the Sphase, while low levels of NO facilitate entry into mitosis apically. ${ }^{6}$ Moreover, PCD that normally occurs in the NT during these embryonic stages is blocked by the inhibition of endogenously produced $\mathrm{NO}$, using nitric oxide synthase (NOS) inhibitors. ${ }^{7}$ These findings prompted us to search for extracellular factors that modulate NOS activity in vivo, thereby controlling cell numbers in the NT.

Compelling evidence makes the extracellular factor, bone morphogenetic protein (BMP), which is expressed in the dorsal NT along the A-P axis at these embryonic stages, ${ }^{8}$ an attractive candidate. BMPs constitute a subclass of the transforming growth factor- $\beta$ superfamily of soluble proteins. Originally characterized by their osteogenetic activity, ${ }^{9,10}$ BMPs are expressed throughout embryogenesis, playing pivotal roles in mesoderm patterning and neural plate induction. ${ }^{11-13}$ The vertebrate neural ectoderm undergoes a period of rapid proliferation and morphogenetic movements to form an NT. This involves signals originating from adjacent tissues that induce dorsal-ventral $(D-V)$ and $A-P$ identities on neural precursor cells. ${ }^{14}$ Initially, BMPs are expressed at high levels in non-neural ectoderm and later also in the roof plate of the NT. ${ }^{8,15,16}$ A BMP activity gradient across the D-V axis of the NT induces dorsal identity markers indicative of neural crest or dorsal interneuron precursors. ${ }^{17-20}$ BMPs also induce apoptosis in the early developing central nervous system (CNS), ${ }^{16-21}$ neuronal differentiation in mid-gestation of CNS precursors ${ }^{22,23}$ and glial differentiation in late embryonic or adult CNS precursors. ${ }^{24}$ 
Here, we investigate the possibility that locally produced extracellular factors, such as BMP and its antagonists, are involved in the regulation of cell numbers in the NT either by driving cells into the cell cycle or by controlling PCD. Here, we show that BMP-4 induces PCD and promotes the entry of neuroepithelial cells into the S-phase in a concentrationdependent manner by increasing NOS activity. NOS inhibitors and BMP antagonists, such as follistatin and noggin, lower endogenous NO levels, reduce PCD and facilitate mitosis. This establishes a balance between cell proliferation and $\mathrm{PCD}$. In addition, we demonstrate that adequate NO levels regulated by the BMP/NO pathway are required for normal NT formation. Prolonged exposure to high or low NO could be responsible for NT defects.

\section{Results}

\section{Ectopic BMP-4 positionally regulates PCD and the S-phase across the D-V axis of the NT}

In the chicken embryo, during the time of NT closure and before the onset of neuronal differentiation, regulation of cell numbers in the NT depends mostly on the level of cell proliferation and PCD. ${ }^{25}$ To explore the molecular mechanisms that locally regulate PCD and cell proliferation in early NT development, we studied the role of BMP-4 in cell number regulation at the time of NT closure. In light of the fact that BMP-4 induces apoptosis in the rhombencephalic neural crest of the chicken embryo, ${ }^{26}$ we hypothesized that BMP-4 could be one of the extracellular factors responsible for the endogenous pattern of cell death. Such cell death had previously been observed along the A-P axis of the NT of the eight to 12 somite stage embryos at the time of NT closure. $^{5}$ To test this hypothesis, beads loaded with BMP-4 $(113 \mu \mathrm{g} / \mathrm{ml})$ were implanted in the lumen of the NT of eight to nine somite stage embryos, at the position of somite 5 , and incubated in ovo for $6 \mathrm{~h}$. To characterize the local effects of BMP-4 on cell death, the embryos were stained with neutral red to visualize the pattern of cell death around the bead. An increase in the number of cells stained with neutral red was observed around the BMP-4 beads (Figure 1a), compared to the normal pattern of staining observed around the control beads (Figure $1 \mathrm{~b}$ ). To verify that the neutral red staining by BMP-4 represents a bona fide PCD, we analyzed NT transverse sections around the bead, by double labeling with propidium iodide (PI) to determine nuclear morphology, and with CM1 antibodies, which cross react with the chick orthologue of caspase-3, and specifically identifies the active cleaved form. ${ }^{27}$ Significant numbers of cells induced by BMP. 4 to undergo PCD were found in the dorsal NT, as judged by localized caspase-3 activity (green) and by typical pyknosis of the nuclei (red) (Figure 1c and d). These results suggest that within $6 \mathrm{~h}$ of local exposure to BMP-4, a caspase-3-like activity is induced in the dorsal half of the NT. To quantify the effect of BMP-4 on PCD, and cell cycle progression, we implanted into the NT beads loaded with decreasing concentrations of BMP$4(113-0.113 \mu \mathrm{g} / \mathrm{ml})$. Cells in the S-phase were identified by bromodeoxyuridine (BrdU) incorporation for the last $2 \mathrm{~h}$ of the experiment. Serial NT transverse sections around the beads were stained with PI and with anti-BrdU antibodies. The data
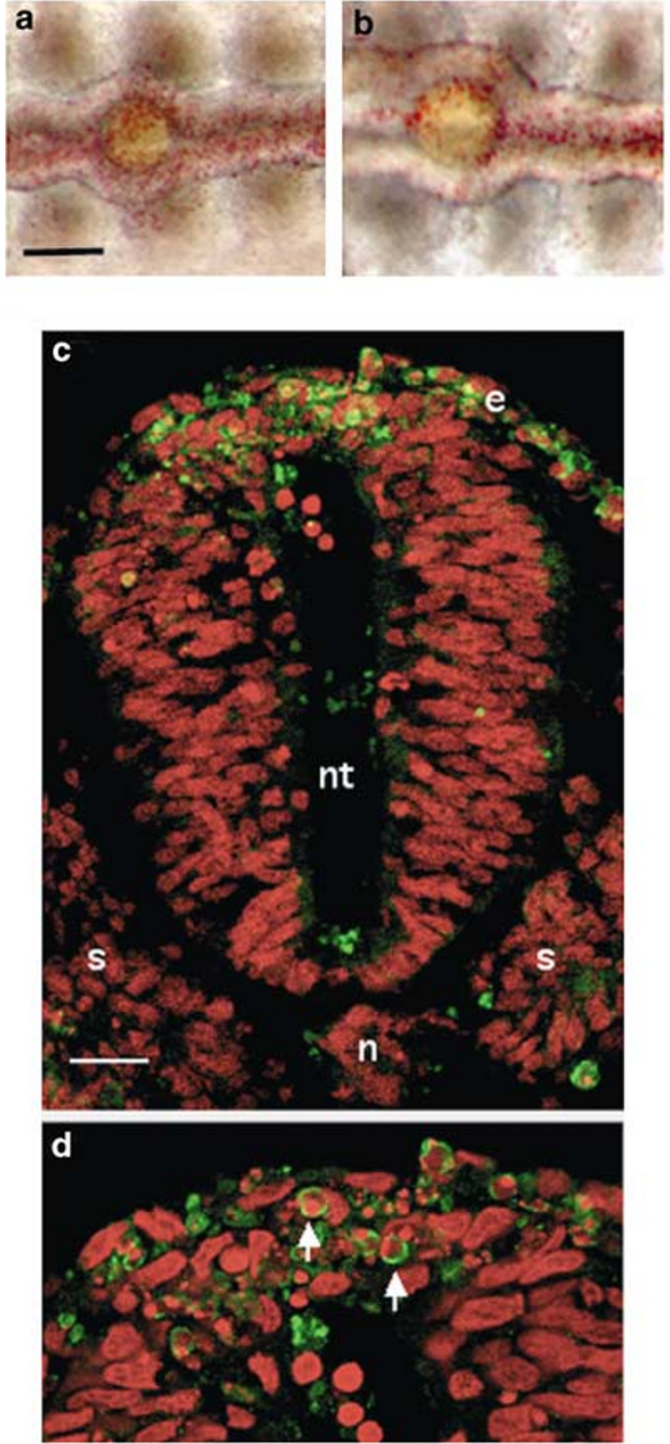

Figure 1 BMP-4-implanted bead locally induces PCD in the NT. BMP-4 or PBS (control) soaked beads (50-100 $\mu \mathrm{m}$ in size) were implanted in the NT at the level of somite four to five of eight to nine somite embryos in ovo and incubated at $38^{\circ} \mathrm{C}$ for $6 \mathrm{~h}$. Embryos that developed into 12 to 14 somites were taken for analysis. PCD was assessed qualitatively by neutral red staining in micrographs in (a) and (b) shows the difference in the pattern of neutral red staining around the implanted BMP-4 (a) and control (b) beads. (c) and (d) shows a confocal micrograph of the dorsal localization of BMP-4 bead induced PCD in an NT transverse section taken near the BMP-4 bead, which was double labeled by immunofluorescence with CM1 antibodies that detect caspase-3-like activity in the cytoplasm of the apoptotic cells (green) and by PI (red) that stains all nuclei to assess for pyknosis of apoptotic cells. (d) is two times confocal magnification of $C$ ( $\times 40$ objective); arrows indicate two examples of double-labeled apoptotic cells in the dorsal NT in detail. e: ectoderm; n: notochord; nt: neural tube; s: somite. Size bar $20 \mu \mathrm{m}$

presented in Figure 2 show that BMP-4 induced PCD significantly in a dose-dependent manner (Figure 2a), had no effect on the proportion of cells undergoing mitosis (Figure $2 b$ ), but increased substantially the number of cells entering the S-phase (Figure 2c). Interestingly, BrdU-positive nuclei showed a normal D-V distribution in the NT (data not shown). These results suggest that the BMP signal is 

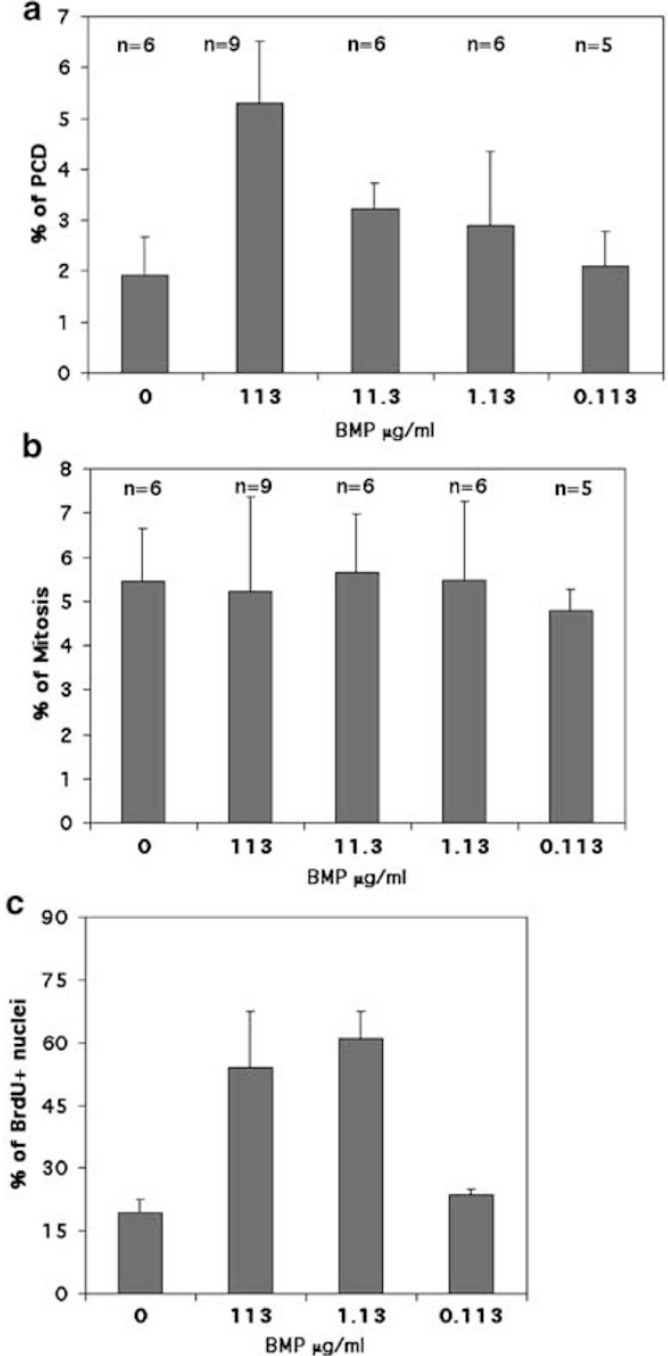

Figure 2 Concentration-dependent effect of BMP-4 on PCD, mitosis and the Sphase. Beads were soaked in four different BMP-4 10-fold dilutions, starting at $113 \mu \mathrm{g} / \mathrm{ml}(1: 1)$ diluted down to $0.113 \mu \mathrm{g} / \mathrm{ml}(1: 1000)$. Beads were implanted in the NT between somites 4 and 5 of eight to nine somite stage embryos in ovo for $6 \mathrm{~h}$. Transverse NT sections equivalent to $300 \mu \mathrm{m}$ in length, around the bead area, were stained with PI to quantitate the proportion of PCD (a) and mitosis (b) from total nuclei identified by their characteristic nuclear morphologies (nuclear pyknosis and mitotic figures, respectively). The proportion of BrdU incorporation (c) was determined in NT transverse sections from three embryos double labeled with $\mathrm{PI}$ and anti-BrdU antibodies. The results are expressed as mean + S.D. An average of 4000 cells were scored per embryo. One-way ANOVA with post hoc test using Tukey B method found a significant difference between groups: in (a) $113 \mu \mathrm{g} / \mathrm{ml} \mathrm{BMP}-4$ is different from the rest and in (c) 113 and $1.13 \mu \mathrm{g} / \mathrm{ml} \mathrm{BMP}-4$ are similar and different from the rest

transduced differently along the D-V axis, according to local BMP concentrations.

\section{BMP-4 induction of PCD and promotion of entry into the S-phase is mediated by NOS activity}

Having shown the effects of BMP-4 on PCD and on cell cycle progression, we next tested whether there is a direct effect of BMP on NOS activity that was previously shown to be a modulator of PCD and cell cycle progression. ${ }^{6,7} \mathrm{BMP}-4$ beads
$(113 \mu \mathrm{g} / \mathrm{ml})$ were implanted into the NT, as described above in the presence or absence of $N^{G}$-methyl-L-arginine (L-NMMA), an L-arginine analogue that acts as an NOS inhibitor. NO production in the developing NT was monitored by using the cell-permeable fluorescent $\mathrm{NO}$ indicator 4,5-diaminofluorescein diacetate (DAF-2DA), applied on top of the embryos in ovo at the end of the $6 \mathrm{~h}$ incubation. Embryos were removed at the end of the incubation and analyzed under a confocal fluorescent microscope. Figures 3a-c show image frames of three $3 \mathrm{D}$ projection videos made from confocal images of $136 \mu \mathrm{m}$ deep longitudinal optical serial sections of the NT, taken at the position of the implanted control (PBS) bead and the implanted BMP-4 bead, in the presence or absence of LNMMA, respectively (see online supplemental material, Figure 3a/video 1.mov, Figure 3b/video 2.mov and Figure 3c/ video 3.mov). This analysis revealed that while the endogenous detection of NO by DAF-2DA fluorescence is localized in the ectoderm and adjacent dorsal NT (Figure 3a/video 1.mov), BMP-4 clearly induces NO production deeper in the NT judged by the fluorescence observed around the BMP-4 bead (Figure 3b/video 2.mov). In embryos treated with the NOS inhibitor L-NMMA, a considerable decrease in NO levels is detected (Figure 3c/video 3.mov).

Representative NT transverse sections of similar experiments described above were stained with $\mathrm{PI}$ to reveal pyknotic nuclei. While around the untreated control bead the few pyknotic nuclei were distributed at different $\mathrm{D}-\mathrm{V}$ positions (arrows Figure 4a), pyknosis was consistently observed in the dorsal NT around the BMP-4 bead (arrows Figure 4b). The NOS inhibitor L-NMMA caused a significant reduction in the extent of pyknosis induced by BMP-4 (Figure 4c). To test whether the effect of BMP-4 on the promotion of the S-phase takes place via NOS activity, we applied BrdU for the last $2 \mathrm{~h}$ of the experiment. Representative NT transverse sections double labeled with $\mathrm{PI}$ and anti-BrdU show that the endogenous levels of BrdU incorporation in the untreated control sections (Figure 4d) are much lower than in the BMP-4-

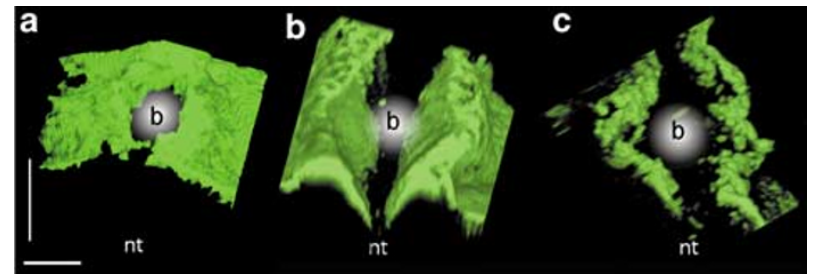

Figure 3 BMP-4 beads induce NOS activity in the NT. Confocal micrograph projection showing in situ localization of NO in vivo around BMP-4 bead implanted in the NT using DAF2-DA. The micrograph represents a projection series of $136 \mu \mathrm{m}$ thick longitudinal optical sections of the NT at the control bead and BMP-4 bead area from three 12 somite embryos (a-c). Control beads soaked in PBS and BMP-4 $(113 \mu \mathrm{g} / \mathrm{ml})$ soaked beads were implanted with or without L-NMMA in the NT of eight to nine somite embryos for $6 \mathrm{~h}$. (a) Endogenous NO localization detected around the control PBS bead by DAF-2DA fluorescence in green compared to the (b) BMP-4 bead effect on the DAF-2DA fluorescence around the bead area. (c) Shows the remaining DAF-2DA fluorescence around the BMP-4 bead with $50 \mathrm{mM}$ L-NMMA NOS inhibitor. Note that the fluorescence indicator of NO is absent inside the NT as a result of specific inhibition of NOS. b: drawing of a bead to illustrate the implanted site; nt: NT. The horizontal scale bar represents $50 \mu \mathrm{m}$, the vertical size bar represents $120 \mu \mathrm{m} z$ scan (for rotating projections of (a-c), please see video 1.mov, video 2.mov and video 3 .mov. respectively) 
treated sections (Figure 4e). Cotreatment with BMP-4 and LNNMA resulted in a reduction of BrdU-positive nuclei (Figure 4f), as compared with control levels (Figure 4d). Note that in all sections, BrdU-positive nuclei were evenly distributed across the D-V axis of the NT.

Figure $4 \mathrm{~g}$ shows the quantitative analysis of the effects of BMP-4 on mitosis and PCD in the NT. While ectopic BMP-4 increases the proportion of PCD, cotreatment with L-NMMA reverses the BMP-4 effect. In contrast, mitosis is not affected by BMP-4. The increase in mitosis and decrease in PCD by LNMMA treatment is in accord with our previous observations that low NO levels produced by direct NOS inhibition facilitate
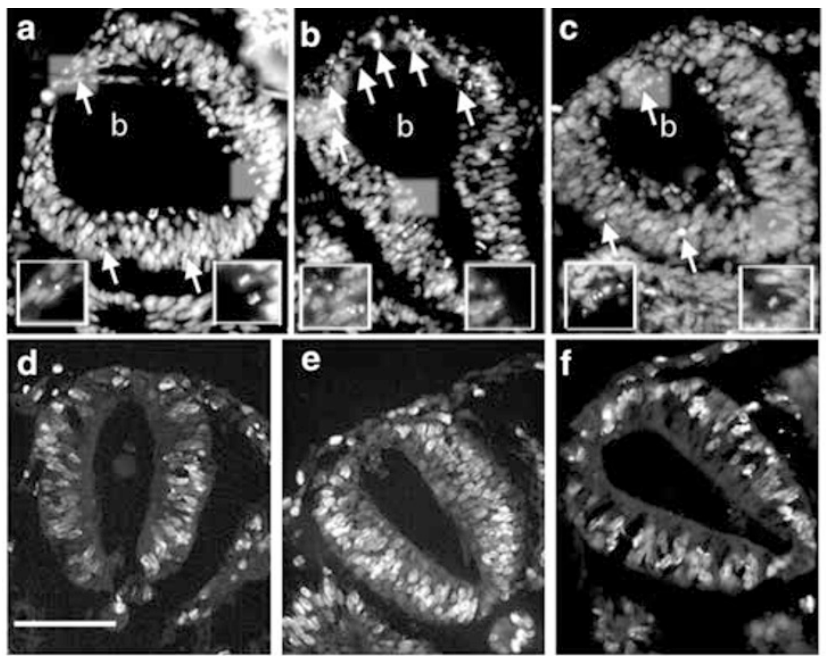

g
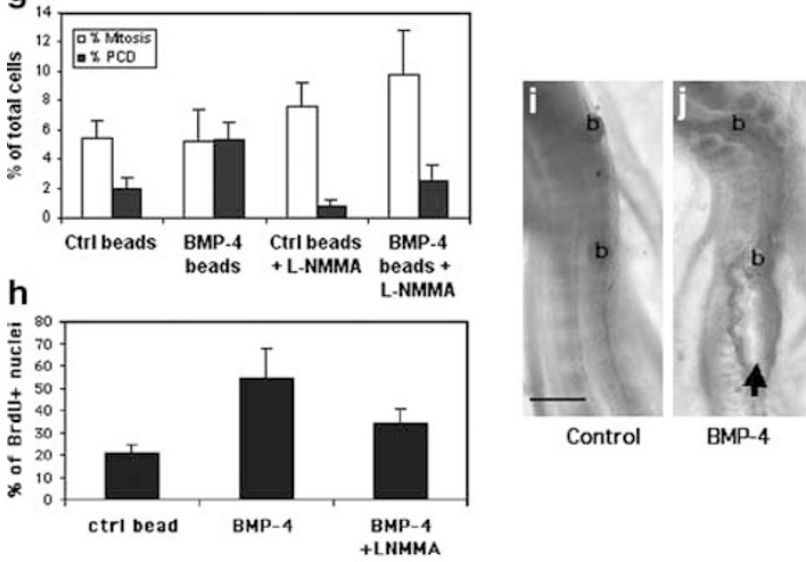

k
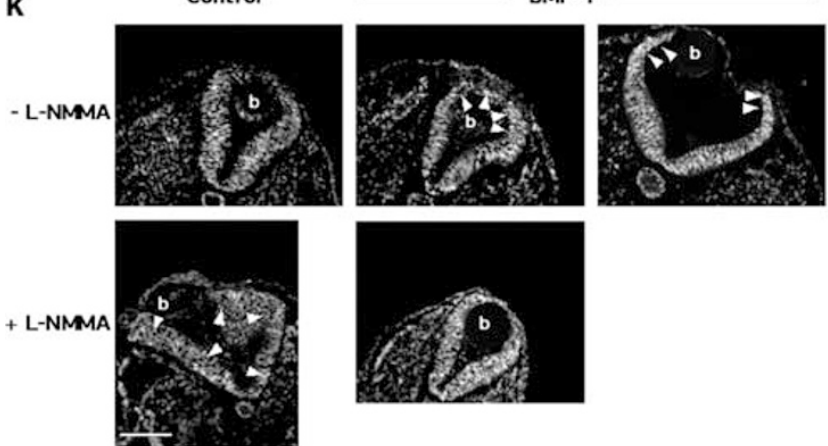

mitosis $^{6}$ and inhibit PCD in the NT neuroepithelium. ${ }^{7}$ A quantitative analysis of the BrdU incorporation experiments (Figure 4h) shows that L-NNMA can lower the effect of BMP-4 on the number of cells that enter the S-phase to almost control levels. L-NMMA treatment alone does not affect the endogenous proportion of BrdU-positive cells (data not shown), as had been shown previously. 6,7

These results taken together argue that ectopic BMP-4 induces PCD and promotes entry into the S-phase by increasing NOS activity in the developing NT. Notably, while the induction of PCD is restricted to the dorsal half of the NT, the effect on cell cycle progression is evenly distributed across the $\mathrm{D}-\mathrm{V}$ axis of the NT.

Next, we performed experiments to test the impact of the BMP/NO effects (particularly on PCD) on normal NT formation in $24 \mathrm{~h}$ treated embryos as seen in Figure 4i-k (see online supplementary material). Interestingly, under these experimental conditions, BMP-4-loaded beads (producing high NO levels) and L-NMMA treatment (low NO levels) inflicted NT defects. Yet, normal NT morphology was observed when both treatments were combined. Interestingly, the prolonged BMP4-mediated induction of PCD in the dorsal NT caused massive cell loss that can result in an open NT by the elimination at the midline of the roof plate forerunner. These results demonstrate the importance of cell number control by BMP/NO and the requirement of adequate NO levels for normal NT development.

Figure 4 BMP-4 induces PCD and promotes the S-phase via NOS activity. BMP- 4 beads and control beads $(113 \mu \mathrm{g} / \mathrm{ml})$ were implanted into the NT for $6 \mathrm{~h}$ in the presence or absence of L-NMMA (NOS inhibitor). (a-c) Micrographs show the fluorescence of Pl-stained images of transverse NT sections through the implanted control (a) and BMP-4 beads (b and $\mathbf{c}$ ). Localized PCD in the dorsal NT induced by the BMP-4 bead is assessed by pyknosis (indicated by arrows) in the PI-stained NT section (b). This effect on PCD is not visible in PI-stained NT sections of BMP-4-positive L-NMMA $(50 \mathrm{mM})$ treatment (c). b: bead. Typical examples of the nuclear morphologies of mitosis and pyknosis visualized by $\mathrm{PI}$ staining in the NT sections of (a-c) are indicated by a shaded box. Magnification $(\times 2)$ of these boxes are shown at the bottom left (pyknosis) and right (mitosis) in each micrograph. (d-f) Transverse NT sections showing BrdU-positive nuclei distributed throughout the D-V axis in untreated (d), BMP-4 treated $(113 \mu \mathrm{g} / \mathrm{ml})$ (e) and BMP-4-positive L-NMMA treated (f). Note that BMP-4 increases the amount of BrdU-positive nuclei in the NT, while this effect is blocked with LNMMA. Size bar $50 \mu \mathrm{m}$. (g) Quantitative analysis of the proportion of PCD and mitosis in PI-stained NT sections. (h) Shows the proportion of double-labeled BrdU positive from total PI-stained nuclei. In (g) and (h), a total of $300 \mu \mathrm{m}$ of NT sections around the implanted beads were analyzed. The results are expressed as mean \pm S.D. An average of 4000 cells were scored per embryo. In (g), the significance of the treatment was estimated by two-way ANOVA on \% PCD for: LNMMA, $P<0.001$; for BMP-4, $P<0.001$ and on $\%$ of mitosis for: L-NMMA, $P=0.001$. In (h), one-way ANOVA with post hoc test using Tukey B method found a significant difference between the three groups; untreated, BMP-4 and BMP-4-positive L-NMMA. (i-k) The BMP-4/NO pathway is required for normal NT formation. (f) and (g) Whole-mount neutral red staining of embryos (stage $17 \mathrm{HH}$ ) to visualize cell death, which were treated with implanted control PBS (i) and $113 \mu \mathrm{g} / \mathrm{ml} \mathrm{BMP}-4$ (j) -loaded beads and incubated for $24 \mathrm{~h}$. An arrow points at the site with evident open NT, caudal to the posterior BMP-4 bead. Size bar $200 \mu \mathrm{m}$. (k) Micrographs showing representative examples of NT transverse sections stained by PI of control PBS and BMP-4-loaded beads, treated embryos with or without $50 \mathrm{mM}$ L-NMMA for $24 \mathrm{~h}$. Arrowheads indicate localized pyknosis. NT defects with a high incidence of dorsal PCD and open NT were observed in BMP4-treated embryos. These effects were rescued in BMP-4-positive L-NMMA showing a morphology similar to that with control beads. Embryos with control beads treated with L-NMMA showed high incidence of NT defects. Size bar $50 \mu \mathrm{m}$ 


\section{BMP antagonists reduce endogenous NO levels required for entry into mitosis}

It is shown above that BMP signaling exerts its activity in the NT neuroepithelium in a concentration-dependent manner via NOS activity. At high BMP-4 concentrations, the higher NO levels produced increase PCD and promote entry of cells into the S-phase, with no effect on the level of mitosis. Therefore, BMP signaling must be strictly downregulated to lower NO levels that will allow an adequate number of cells to cycle in the neuroepithelium toward mitosis. ${ }^{6,7}$ To further elucidate the mechanism by which BMP-4 affects cell numbers by regulating $\mathrm{NO}$ levels in the NT, we used the BMP antagonists follistatin ${ }^{15,28}$ and noggin ${ }^{29}$ to try to neutralize the effects of ectopic BMP-4. BMP-4-loaded beads $(113 \mu \mathrm{g} / \mathrm{ml})$ were implanted in ovo into the NT of eight to nine somite embryos at somite 5 , and either $0.5 \mathrm{mg} / \mathrm{ml}$ follistatin or $0.8 \mathrm{mg} / \mathrm{ml} \mathrm{noggin}$ were applied on top of the embryos, which were incubated for $6 \mathrm{~h}$. In parallel, $0.5 \mathrm{mg} / \mathrm{ml}$ follistatin or $0.8 \mathrm{mg} / \mathrm{ml}$ noggin were loaded onto beads and implanted into the NT to test their effects on endogenous BMP and cell numbers in the NT. Figure 5a summarizes a quantitative analysis of the proportion of cells undergoing mitosis, PCD and BrdU incorporation. Data were collected from NT transverse sections around the beads and double labeled with $\mathrm{PI}$ and anti-BrdU. The results show that, while follistatin and noggin increase mitosis in the presence or absence of BMP-4, they completely abolished the BMP-4 effect on $\mathrm{PCD}$ and significantly reduced the effect of BMP-4 on entry of the cells into the S-phase. These results suggest that follistatin and noggin can serve as regulators of BMP-4 activity in the NT. This adds significantly to our understanding of the molecular mechanism involved in cell number control in the developing NT.

To determine whether this pathway of BMP signal antagonism leads to the control of NOS activity, we tested the capability of BMP antagonists to lower endogenous NOS activity. NOS activity assays were carried out with extracts made of NT and somites dissected from embryos, which were cultured for $6 \mathrm{~h}$ in the presence of $50 \mu \mathrm{g} / \mathrm{ml}$ follistatin, $11 \mu \mathrm{g} / \mathrm{ml}$ noggin or $10 \mathrm{mM}$ L-NMMA. NOS activity was assayed by measuring the conversion of L-Arginine $\left[\mathrm{H}^{3}\right]$ to $\mathrm{L}$-citrulline $\left[\mathrm{H}^{3}\right] .{ }^{6}$ Compared to untreated controls $(6.2 \pm$ S.D. $1.7 \mathrm{nmol} \mathrm{L}-$ citrulline $\left[\mathrm{H}^{3}\right] / \mathrm{mg}$ protein), follistatin-treated embryos produced $27 \%$ less L-citrulline[ $\left.\mathrm{H}^{3}\right]$ (4.6 \pm S.D. $0.4 \mathrm{nmol}$ L-citrulline $\left[\mathrm{H}^{3}\right] /$ mg protein), noggin-treated embryos produced $47 \%$ less L-citrulline $\left[\mathrm{H}^{3}\right]\left(2.9 \pm\right.$ S.D. $0.9 \mathrm{nmol} \mathrm{L}$-citrulline $\left[\mathrm{H}^{3}\right] / \mathrm{mg}$ protein) similar to L-NMMA-treated embryos that produced $49 \%$ less L-citrulline $\left[\mathrm{H}^{3}\right]$ (3.2 \pm S.D. $0.03 \mathrm{nmol}$ L-citrulline $\left[\mathrm{H}^{3}\right] / \mathrm{mg}$ protein). These values are averages of three independent experiments that were performed with extracts prepared from dissected NTs of a pool of 12 embryos per treatment. These results suggest that by antagonizing endogenous BMP, both follistatin and noggin reduce endogenous NO levels in the developing NT of the chicken embryos.

We have previously shown that high NO levels produced by the NO donor $S$-nitroso- $N$-acetyl-penicillamine (SNAP) promoted entry of cells into the S-phase, while the NOS inhibitor L-NMMA facilitated mitosis. ${ }^{6}$ Treatment with a combination of SNAP and L-NMMA resulted in unchanged mitosis. Similarly, the results shown in Figure $5 \mathrm{~b}$ demonstrate that a combination of SNAP and follistatin reverses the follistatin-dependent effect on mitosis and PCD. These results further support our proposal that NO is a downstream mediator of a BMP-4 pathway; thus low NO levels are needed to facilitate mitosis.

We reasoned that the antagonistic activities of BMP-4 and follistatin may play a role in the promotion of cells to enter mitosis. Based on the fact that as little as $2 \mathrm{~h}$ are required for BrdU-positive nuclei to reach mitosis in an L-NMMA-treated neuroepithelium, while at least $5 \mathrm{~h}$ are required in untreated controls and SNAP-treated embryos (data not shown), we designed the following experiment. BMP-4 beads were implanted into the NT of eight to 10 somite embryos and incubated for $6 \mathrm{~h}$. BrdU was added $2.5 \mathrm{~h}$ after the onset of the incubation, which was followed by the addition of follistatin on top of the embryos $30 \mathrm{~min}$ later. We tested the possibility that BrdU-labeled nuclei can be driven into mitosis by follistatin during the remaining $3 \mathrm{~h}$ of incubation. Confocal micrographs (shown in Figure 5c) were taken from the bead area in NT transverse sections double labeled with $\mathrm{PI}$ (red) and anti-BrdU (green). The images were taken from untreated control embryos and embryos treated with BMP-4, follistatin or BMP-4 plus follistatin. Yellow-stained nuclei testify for colocalization of both BrdU and PI labels. Notably, doublelabeled PI/BrdU-positive mitotic nuclei appeared at the end of the incubation period only in the ventricular zone of the NT in embryos treated with follistatin plus BMP-4 or follistatin alone (see arrows). These results suggest that follistatin antagonizes BMP-4 activity, thereby lowering NO levels. The low NO levels allow BrdU-positive nuclei to progress toward mitosis within $3 \mathrm{~h}$.

\section{Discussion}

During early NT development, endogenous NO regulates cell cycle progression ${ }^{6}$ and cell numbers. ${ }^{7}$ Yet, the extracellular factors involved in the regulation of NO levels in the NT were not identified. In the present study, we report that BMP-4 induces NOS activity in the neuroepithelium of eight to 12 somite chicken embryos. Figure 6 presents a scheme of a proposed mechanism by which BMP-4 affects NT cell cycle progression and $\mathrm{PCD}$ in an NOS-mediated manner. The balance between BMP-4 (red) and its antagonists such as follistatin and noggin (blue) locally modulates NOS activity in the neuroepithelium. As a result, levels of NO change and consequently PCD levels and cell cycle progression are affected. When BMP is released from the effects of its antagonists, due to high local concentration, cells undergo PCD via NOS in the dorsal NT where BMP-4 is endogenously expressed. $^{8}$ Remarkably, in this scenario, the BMP/NOS pathway apparently induces Wnt signaling. In preliminary studies in embryos treated with the BMP antagonist follistatin or NOS inhibitor L-NMMA that reduce NO levels, we observed a reduction in $\beta$-catenin expression (data not shown), suggesting a decrease in Wnt signaling. This is in accord with previously reported findings that dorsal medial Wnt signaling is responsible for equal entry of neural precursor cells into the S-phase dorsoventrally at this early developmental stage in the NT by inducing in a similar manner the expression of late $\mathrm{G} 1$ cyclins $D 1$ and $D 22^{25}$ The low NO levels 
a

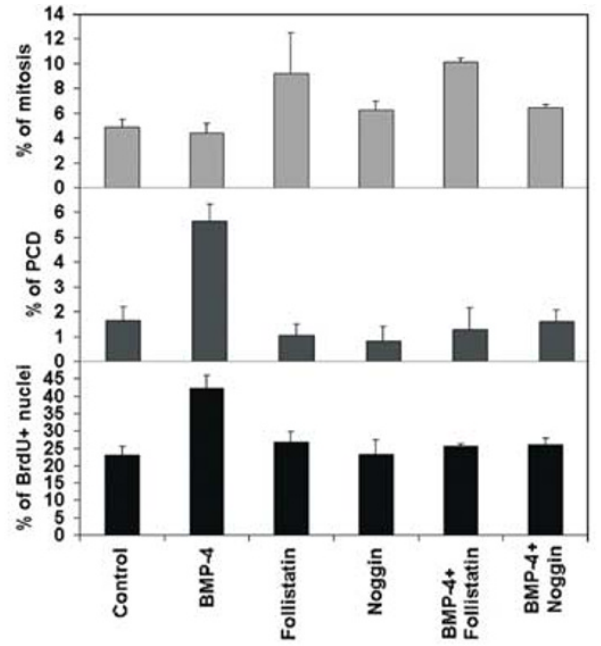

b

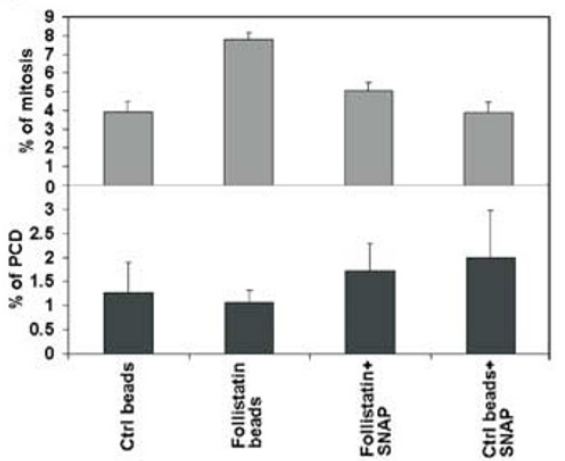

c
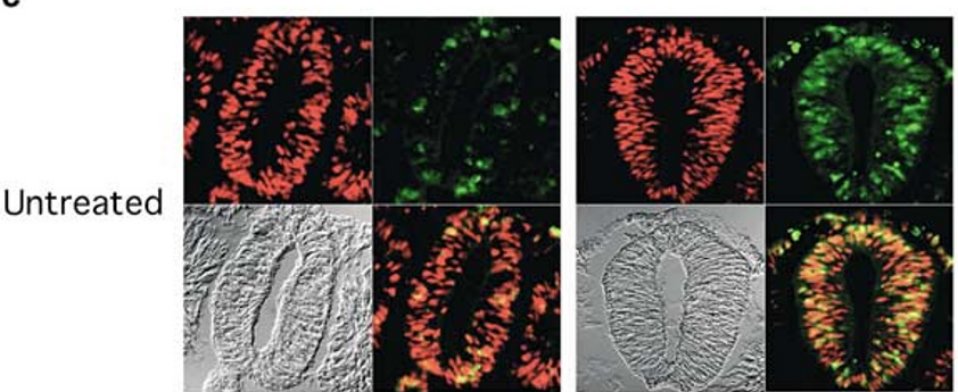

Red $=\mathrm{PI}$

Green $=\mathrm{BrdU}+$

Yellow = merged

BMP-4
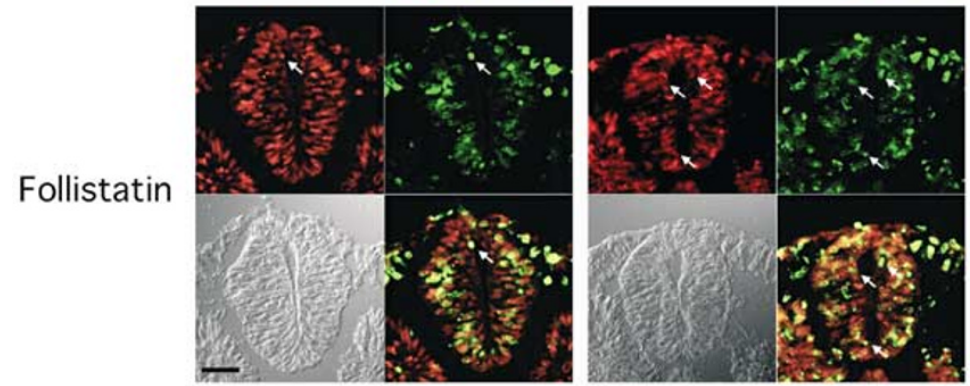

BMP- 4 +

Follistatin

Figure 5 BMP regulation of cell numbers requires a BMP antagonist to modulate NO levels to promote cell cycle progression. (a) Quantitative analysis of the proportion of mitosis, PCD and BrdU incorporation in embryos treated with the control, BMP-4 $(113 \mu \mathrm{g} / \mathrm{ml})$, follistatin $(500 \mu \mathrm{g} / \mathrm{ml})$ or noggin $(800 \mu \mathrm{g} / \mathrm{ml})$ beads and BMP-4 beads with follistatin or noggin (in $20 \%$ pluronic gel) for $6 \mathrm{~h}$. NT sections around the beads were double stained by PI and anti-BrdU antibodies and analyzed as explained in Figure 2. The results are expressed as the mean \pm S.D. calculated from $n=4$ embryos under each condition. An average of 4000 nuclei were scored per embryo. The significance of the treatment effect was estimated by two-way ANOVA on \% of mitosis: for follistatin, $P<0.001$; for noggin, $P<0.001$, on $\%$ of PCD and on $\%$ of BrdU positive: for all treatments $P<0.007$. (b) Follistatin effects on PCD and mitosis are reverted by NO donor SNAP. Quantitative analysis of the proportion of mitosis and PCD on Pl-stained NT sections of embryos treated with $500 \mu \mathrm{g} / \mathrm{ml}$ follistatin or control beads in the presence or absence of $2.5 \mathrm{mM}$ SNAP for $6 \mathrm{~h}$. The results are expressed as the mean \pm S.D. calculated from $n=6$ embryos under each condition. An average of 4000 nuclei were scored per embryo. The significance of the treatment effect was estimated by two-way ANOVA on \% of PCD: for SNAP $P=0.02$, on $\%$ of mitosis: for follistatin, for SNAP and for follistatin-positive SNAP $P<0.001$. (c) BMP-4 or control beads $(113 \mu \mathrm{g} / \mathrm{ml})$ were implanted in the NT of eight to nine somite embryos and incubated for $6 \mathrm{~h}$. BrdU was applied after $2 \mathrm{~h}$ of incubation and $500 \mu \mathrm{g} / \mathrm{ml}$ follistatin (in $20 \%$ pluronic gel) treatment was added on top of the embryos 30 min later for the remaining incubation period. Confocal micrographs of NT transverse sections double labeled by PI (red) and by BrdU immunofluorescence (green), taken near the bead, of an untreated control, BMP-4-treated, BMP-4 plus follistatin or follistatin-treated embryos. The lower left panel of each treatment shows the respective DIC transmission image of the NT section. The merged red and green confocal images resulting in pixel colocalization, where double labeled nuclei become yellow. Confocal analysis of multiple sections from all four treatments revealed that no BrdU-labeled nuclei were visibly engaged in mitosis in untreated or BMP-4-treated embryos by the end of the $6 \mathrm{~h}$ incubation. Size bar $20 \mu \mathrm{m}$

(Figure 5) and presumably the reduction of Wnt signaling may promote mitosis by allowing the transcription of relevant G2/M cyclins enabling cell cycle progression (Figure 6). This assumption is in accord with the observation carried out by Megason and McMahon $^{25}$ that dominant active $\beta$-catenin upregulates in the developing spinal cord the expression of cyclin $D 1$ and cyclin $D 2$ but not the G2/M cyclins $A 1$ and $B 3$.
Moreover, the Wnt proliferative activity that we and others observed across the $\mathrm{D}-\mathrm{V}$ axis in early NT development changes later with the increase in NT size at later stages. This limits Wnt proliferative activity dorsally and induces neural differentiation ventrally. ${ }^{25}$ This may explain how the BMP-4 / NO pathway may affect cell cycle progression evenly across the D-V axis at this time in NT development. It could also 


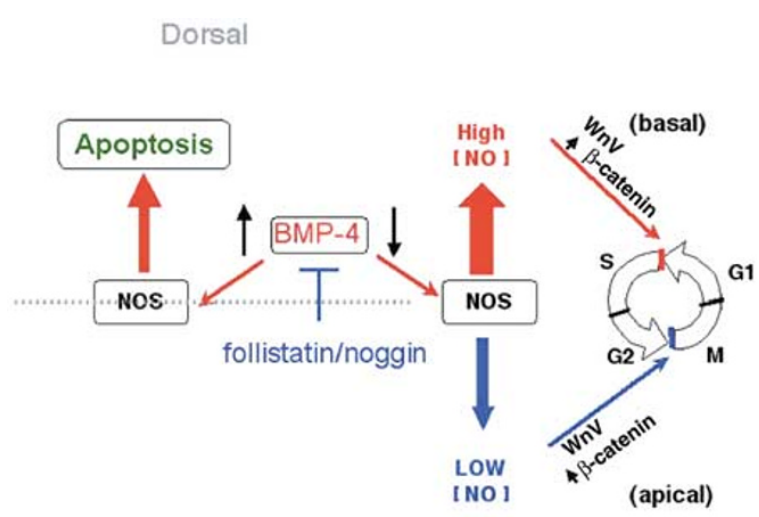

Ventral

Figure 6 Locally available BMP modulates NO concentration, thus regulating cell numbers in the developing NT. BMP-4 as an extracellular growth factor, transduced via a specific cell membrane receptor, activates intracellularly NOS (red route). Increase in NO concentration facilitates the entry of basally positioned cells into the S-phase. This requires nuclei to be basally positioned presumably by activating the canonical Wnt signaling pathway that blocks $\beta$ catenin proteosomal degradation. We have observed an increase in $\beta$-catenin levels in embryo extracts (data not shown). A local BMP-4 antagonist, such as follistatin or noggin, lowers effective BMP levels in the extracellular space (blue route), reduces NOS activity and concomitantly NO levels that presumably result in reduced Wnt signaling (decrease in $\beta$-catenin levels). Low levels of NO facilitate the entry into the M-phase of cells in which nuclei are positioned apically. These effects on the S-phase and mitosis are evenly distributed across the D-V axis. Remarkably, higher concentrations of BMP-4 are probably required to induce high production of NO. This triggers positional apoptosis in the dorsal NT, which can be blocked by the BMP-4 antagonists that lower the NO levels

explain why at later developmental stages when the spinal cord increases in size, the role of BMP in dorsal neural pattern formation is different, being more restricted dorsally. ${ }^{17-20}$ The BMP/NO mediation of the Wnt signaling in NT formation requires further characterization.

The concentration-dependent experiments described here show that high BMP-4 concentrations induce PCD and promote the S-phase. Interestingly, a low BMP-4 concentration $(1.13 \mu \mathrm{g} / \mathrm{ml})$ still promotes the S-phase but cannot induce PCD (Figure 2). These effects of BMP-4 on S-phase promotion are across the D-V axis of the NT (Figure 4d-f), while ectopic BMP-4 induces PCD only in the dorsal half of the NT (see Figures $1 \mathrm{c}$ and $4 \mathrm{a}-\mathrm{c}$ ). This unexpected result suggests that local BMP-4 concentrations along the D-V axis elicit accordingly different signaling pathways that induce caspase-mediated PCD in the dorsal part of the NT on the one hand (Figures $1 \mathrm{c}$ and $\mathrm{d}$ ), and a different pathway that promotes entry into the S-phase across the $\mathrm{D}-\mathrm{V}$ axis on the other, yet both BMP-4 pathways are mediated by NO. Taken together, the BMP-4/NOS pathways are responsible for two different cell fates that are positionally determined dorsoventrally, in the developing NT of the chick embryo according to BMP availability. Our experiments described in Figure 4i-k (on line supplemental data) suggest that prolonged exposure to BMP-4 or L-NMMA $(24 \mathrm{~h})$ could lead to NT defects, with different morphological features. BMP-4 (high NO levels)induced dorsal PCD, as shown previously for $12 \mathrm{~h}$ SNAP treatment, ${ }^{7}$ can cause reopening of the NT inflicted by the progressive elimination of neural precursor cells through PCD at the dorsal midline of the NT. On the other hand, low NO levels produced by L-NMMA cause significant dorsoventral morphological defects that include an increase of PCD and abnormal thickening and closure of the NT. Evidently, BMP-4 overexpression (high NO) and low NO levels produced by LNMMA exert different effects on the neural precursor cell population with deleterious consequences on NT formation. The different effects observed with different NO levels are eliminated when both treatments are combined, resulting in normal NT morphology. This suggests that adequate NO levels produced by BMP-4 are required for normal NT formation. This conclusion is strengthened by the fact that in noggin null mice, excessive cell death and NT closure defects is observed at the dorsal NT midline presumably as a consequence of increased BMP activity. ${ }^{30}$ Further support to this conclusion comes from the premature activation of the BMP-4 target gene Msx-1 in the dorsal NT, which in turn has been implicated in BMP-4-induced apoptosis. ${ }^{16,26}$ BMP signaling activates Smad $1 / 5 / 8$ proteins, which associate with Smad 4 before translocating to the nucleus. The endogenous pattern of activated Smad1/5/8 was recently observed in the 11 somite embryo, across the entire dorsal midline of the NT. ${ }^{31}$ Taking these and our observations together, it may be suggested that BMP-4 induces PCD via a Smad 1/5/8 signal in the dorsal midline of the NT. However, this pattern of activated Smad 1/5/8 cannot explain why BMP-4 transducing signal involved in cell cycle regulation is evenly distributed across the $\mathrm{D}-\mathrm{V}$ axis of the NT. This suggests that there must be another intracellular BMP signal transduction pathway operating via NO involved in promoting cell cycle. Our observation that Wnt signal operates via the BMP/NO pathway strongly supports this possibility. Having observed two different positional BMP-4 effects, we suggest that two BMP-4 transduction pathways exist. This suggestion is supported by several lines of previously published observations. First, the pattern of expression of bmpr-1a and bmpr-1b in the CNS of mouse embryos suggests that they have distinct roles in the transduction of BMP signal. ${ }^{32,33}$ Second, while BMPR-IA is expressed ubiquitously in the NT and promotes BrdU incorporation into the CNS precursor cells, BMPR-IB is restricted to the dorsal NT where BMP is produced. In the dorsal NT, BMP limits precursor cell numbers by causing mitotic arrest, and consequently apoptosis in early gestation and terminal differentiation at mid-gestation embryos. ${ }^{34}$ Here, we establish the impact of high BMP-4 concentrations on neural cells in the dorsal NT in prolonged $24 \mathrm{~h}$ incubations. How the BMP-4/NO pathway is involved in dorsal neural fate patterning of the spinal cord at later developmental stages remains to be investigated.

The ability of BMP-4 to promote entry into the S-phase via NOS induction without concomitantly increasing mitosis, as described here, sheds light on our previous findings that neuroepithelial cells require high NO levels to enter the Sphase, and low NO levels to facilitate mitosis. ${ }^{6}$ It appears that BMP-4 has no direct mitogenic effect on neuroepithelial cells. The effect on mitosis is only observed in the presence of its antagonists follistatin or noggin that lower NO levels (see Figure 5). This effect is restored to normal levels in the presence of the NO donor SNAP. It can therefore be concluded that the availability of the BMP-4 signal, which is 
dependent on its antagonists activity, controls cell numbers via the production of adequate NO levels in the NT that is required for normal NT formation (see Figure 4i-k and respective online supplementary data).

\section{Materials and Methods}

\section{Experimental manipulations on chicken embryos in ovo}

Fertilized White Leghorn chicken eggs were incubated at $38^{\circ} \mathrm{C}$ for $35-38 \mathrm{~h}$ and staged in ovo according to Hamburger and Hamilton $(\mathrm{HH}){ }^{35}$ Experiments were performed in ovo on embryos at eight to 10 somite stage (HH 9). BMP-4 at $113 \mu \mathrm{g} / \mathrm{ml}$ and at lower concentrations (Wyeth Research, MA, USA) or $0.5 \mathrm{mg} / \mathrm{ml}$ follistatin (National Hormone and Pituitary Program, CA, USA), as well as $0.8 \mathrm{mg} / \mathrm{ml}$ noggin (condition medium from noggin overexpressing cells (see below)) were applied to 50-100 $\mu \mathrm{m}$ heparin acrylic beads (Sigma). Proteins were loaded onto beads as described. ${ }^{36}$ Control beads (soaked in PBS) and protein-loaded beads were implanted in the NT simultaneously, at the level of somite 4 . For NOS inhibition, embryos with implanted, BMP-4 beads or control beads, were treated with $50 \mathrm{mM}$ L-arginine analogue L-NMMA (Sigma). To increase NO levels, the NO donor SNAP (Sigma) was added at $2.5 \mathrm{mM}$ concentration on top of follistatin and control bead-implanted embryos. The chemicals were applied in $2 \mu$ l pluronic gel solution $(20 \% \mathrm{w} / \mathrm{v})$ that solidifies on top of the embryo. Eggs were then sealed and incubated at $38^{\circ} \mathrm{C}$ for $6 \mathrm{~h}$. At the end of the incubation, all embryos were staged under a dissecting microscope and those that developed to the 11 to 14 somite stage were fixed in $4 \%$ paraformaldehyde and processed for cryosectioning as described previously. ${ }^{5}$ In $24 \mathrm{~h}$ incubation experiments, BMP-4 and control beads were implanted in eight to 10 somite embryos at two sites in the NT along the A-P axis, the anterior bead at the level of somite 4 and the posterior one caudal to the newly formed posterior somite. Treatments with $50 \mathrm{mML}-\mathrm{NMMA}$ or PBS were applied every $4 \mathrm{~h}$ for the first $12 \mathrm{~h}$ of the incubation period followed by a last application $6 \mathrm{~h}$ later. Embryos were staged and processed for qualitative analysis of cell death and NT morphology, as explained below.

\section{Collection of noggin-conditioned medium}

To obtain noggin in high concentration for bead implantation experiments, $10 \mu \mathrm{g}$ of pcNoggin cDNA plasmid (a gift from Richard Harland's laboratory), encoding the full-length xenopus Noggin homolog ${ }^{37}$ or control pcDNA-1 plasmid vector, was transfected using calcium phosphate method into HEK 293T cells cultured in three $9 \mathrm{~mm}$ dishes with Dulbecco's modified Eagle's medium (DMEM) containing glucose, Glutamax-1 and sodium pyruvate supplemented with $10 \%$ fetal bovine serum and penicillin-streptomycin (Gibco). pEGFP cDNA plasmid $(0.25 \mu \mathrm{g})$ (Clontech) was cotransfected as a reporter of gene expression. Green fluorescence protein expression was verified under a fluorescent inverted microscope $48 \mathrm{~h}$ after transfection. Then, noggin expressing and transfected control cells were washed and cultured in DMEM without serum. The conditioned media with or without noggin were collected from the plates for 2 consecutive days and the total volume was concentrated down to $150 \mu \mathrm{l}$ and dialyzed simultaneously in a vivaspin 20 (cutoff MW $10000 \mathrm{kDa}$ ) (Vivascience, Sartorius AG, Germany) by centrifugation at $1500 \times g$ at $4^{\circ} \mathrm{C}$ using a bench top centrifuge. The protein contents of the two conditioned mediums were determined by colorimetry using the BioRad protein assay following the manufacturer's instructions (Bio-Rad laboratories, Gmbh). About 100 -fold more protein was present in a nogginconditioned medium compared to the control.

\section{Neutral red staining of whole embryos}

After 6 or $24 \mathrm{~h}$ incubation, embryos were stained for 5 min with a $5 \mu$ drop of $100 \mu \mathrm{g} / \mathrm{ml}$ neutral red applied on top of the embryo, then removed with their membranes from the eggs, washed in PBS and immediately placed flat, ventral side down in a $35 \mathrm{~mm}$ dish filled with $1 \%$ agarose. Neutral red staining was visualized under an Olympus SZX9 dissecting microscope with bright field illumination and the embryos were photographed using an attached Nikon coolpix 950 digital camera. Digital images were arranged for comparative analysis with Adobe Photoshop 4.0.

\section{Quantitative analysis of apoptosis and mitosis on PI-stained NT sections}

Treated embryos were removed from the eggs and fixed in 4\% PFA/PBS and processed for frozen sectioning into coated gelatin slides as described before. ${ }^{5}$ To quantitate the proportion of mitotic and apoptotic cells in the NT around the implanted bead, at least 30 serial transverse sections, $10 \mu \mathrm{m}$ thick, were stained with $1 \mu \mathrm{g} / \mathrm{ml} \mathrm{PI}$ to visualize the nuclei, as described previously. ${ }^{5}$ The stained section images were recorded under a Till-Photonics image system attached to an Olympus BX52 fluorescent microscope and stored as 8 bit TIFF files. The images were arranged with Adobe Photoshop 4.0 for quantitative analysis on 1440 dpi in A4 size highquality prints, using Epson Stylus 850 printer.

\section{Immunofluorescence and BrdU incorporation}

Immunodetection of activated caspase-3 in the cytoplasm of apoptotic cells in NT transverse sections of the chick embryo was performed using CM1 affinity purified antibodies (BD-Pharmingen, CA, USA) and double labeled with $\mathrm{PI}$ to visualize pyknosis as described previously. ${ }^{27}$ For BrdU incorporation analysis, a drop of $3.5 \mu \mathrm{l}$ of $40 \mathrm{mM} \mathrm{BrdU}$ was added on top of the embryos in ovo for the final $2 \mathrm{~h}$ of the incubation period or otherwise stated in specific experiments. The embryos were then fixed in cold $4 \%$ PFA/PBS and prepared for cryosectioning. Transverse sections of the NT around the implanted beads were taken for analysis as explained above. The sections were permeabilized in cold methanol for $10 \mathrm{~min}$, rinsed with PBS and then treated with $2 \mathrm{~N} \mathrm{HCl}$ for $40 \mathrm{~min}$ at $37^{\circ} \mathrm{C}$. The sections were neutralized in $0.1 \mathrm{M}$ sodium tetraborate $\mathrm{pH} 7.4$ for $10 \mathrm{~min}$ and rinsed in PBS. Sections were then stained with BU-33 mouse monoclonal anti-Brdu antibody (Sigma) followed by fluorescein-coupled goat anti-mouse immunoglobulin antibodies (Jackson IR) both for $1 \mathrm{~h}$ at room temperature. The sections were finally labeled with PI, mounted and examined under a Till-Photonics image system attached to an Olympus BX52 fluorescent microscope as described above.

\section{In situ localization of NO in NT in whole-mount embryos using DAF2-DA}

Intracellular localization of NO in NT cells of whole-mount embryos was examined using the cell permeable fluorescent NO indicator DAF-2DA (Alexis biochemicals), which is detected by an excitation wavelength of $495 \mathrm{~nm}$ and an emission of $515 \mathrm{~nm}$ under a Zeiss LSM 510 confocal laserscanning microscope. Chick embryos with implanted control beads (PBS) and BMP-4 beads in their NT were treated with or without $50 \mathrm{mM} \mathrm{L-NMMA}$ in ovo as explained above. A $3 \mu \mathrm{l}$ drop of $250 \mu \mathrm{M}$ DAF-2DA diluted in PBS 
was applied on top of the embryos 20 min before the end of the $6 \mathrm{~h}$ incubation period. The embryos were removed from the egg and membranes rinsed in PBS and mounted inside a silicone grease made well on top of a glass microscope slide filled with PBS and covered with a microscope coverslip to build a sealed microchamber. The scan was performed under a $40 \times 1.2 \mathrm{NA}$ water objective to obtain a $141 \mu \mathrm{m}$ thick optical section z-series $512 \times 512$ pixels images. A 3D projection image was built from the sum of these images using Zeiss LSM software. Each frame of the $360^{\circ}$ rotation, JPG images were assembled to produce a moving image using $i$ movie software program for Macintosh.

\section{Detection of NOS activity in chick embryos}

Embryos at the eight to 12 somite stage were removed from the eggs and their membranes and pooled into groups of seven to 10 embryos in a culture dish with $250 \mu \mathrm{l}$ DMEM, with or without $50 \mu \mathrm{g} / \mathrm{ml}$ follistatin or $10 \mathrm{mM}$ L-NMMA, and incubated at $37^{\circ} \mathrm{C}$ with $5 \% \mathrm{CO}_{2}$. L-Arginine $\left[\mathrm{H}^{3}\right]$ $(10 \mu \mathrm{Ci})$ (Amersham, UK) was applied in the last $4 \mathrm{~h}$ of incubation time. Labeled embryos were rinsed in cold $1 \mathrm{mM}$ EDTA-PBS and embryo homogenates were prepared in $10 \mu \mathrm{l} / \mathrm{embryo}$ homogenization buffer (25 mM Tris-HCl (pH 7.4), $1 \mathrm{mM}$ EDTA, $1 \mathrm{mM}$ EGTA). The homogenate was centrifuged at $4^{\circ} \mathrm{C}$ for $30 \mathrm{~min}$ at $14000 \mathrm{rpm}$. NOS activity was measured using NOS detect kit (Stratagene) according to the manufacturer's instructions. Protein contents of the supernatant were determined by colorimetry using the Bio-Rad protein assay following the manufacturer's instructions (Bio-Rad laboratories, Gmbh).

\section{Statistical analysis}

The significance of each treatment alone or combination of two treatments was examined by two-way analysis of variance (ANOVA) after transformation of arc.sin. sq.root of the proportion of mitosis, PCD or BrdU positive to reach a normal distribution. In concentration-dependent experiments with one treatment, significance was examined using oneway ANOVA. When significant differences were indicated in the $F$ ratio test $(P<0.001)$, the significance of differences between means of any of these groups was determined using the modified Tukey B method for multiple comparisons, with $\alpha=0.05$.

\section{Acknowledgements}

This research was supported by The Israel Science Foundation Grant Number 6/10-17.2.

\section{References}

1. Jacobson MD, Weil M and Raff MC (1997) Programmed cell death in animal development. Cell 88: 347-354

2. Raff MC (1992) Social controls on cell survival and cell death. Nature 356 : 397-400

3. Macias D, Ganan Y, Ros MA and Hule JM (1996) In vivo inhibition of programmed cell death by local administration of FGF-2 and FGF-4 in the interdigital areas of the embryonic chick leg bud. Anat. Embryol. 193: 533-541

4. Anlar B, Sullivan KA and Feldman EL (1999) Insulin-like growth factor-I and central nervous system development. Horm. Metab. Res. 31: 120-125

5. Weil M, Jacobson MD and Raff MC (1997) Is programmed cell death required for neural tube closure? Curr. Biol. 7: 281-284

6. Traister A, Abashidze S, Gold V, Plachta N, Karchovsky E, Patel K and Weil M (2002) Evidence that nitric oxide regulates cell-cycle progression in the developing chick neuroepithelium. Dev. Dyn. 225: 271-276
7. Plachta N, Traister A and Weil M (2003) Nitric oxide is involved in establishing the balance between cell cycle progression and cell death in the developing neural tube. Exp. Cell Res. 288: 354-362

8. Liem KFJ, Tremml G, Roelink H and Jessell TM (1995) Dorsal differentiation of neural plate cells induced by BMP-mediated signals from epidermal ectoderm. Cell 82: 969-979

9. Urist MR, Mikulski A and Lietze A (1979) Solubilized and insolubilized bone morphogenic proteins. Proc. Natl. Acad. Sci. USA 76: 1828-1832

10. Wozney JM, Rosen V, Celeste AJ, Mitsock LM, Whitters MJ, Kriz RW, Hewick RM and Wang EA (1988) Novel regulators of bone formation: molecular clones and activities. Science 242: 1528-1534

11. Fainsod A, Steinbeisser $H$ and De Robertis EM (1994) On the function of $B M P-4$ in patterning the marginal zone of the Xenopus embryo. EMBO J. 13: 5015-5025

12. Graff JM (1997) Embryonic patterning: to BMP or not to BMP, that is the question. Cell 89: 171-174

13. Sasai $Y$ and De Robertis EM (1997) Ectodermal patterning in vertebrate embryos. Dev. Biol. 182: 5-20

14. Altmann CR and Brivanlou AH (2001) Neural patterning in the vertebrate embryo. Int. Rev. Cytol. 203: 447-482

15. Fainsod A, Dießler K, Yelin R, Marom K, Epstein M, Pillemer G, Steinbeisser H and Blum M (1997) The dorsalizing and neural inducing gene follistatin is an antagonist of BMP-4. Mech. Dev. 63: 39-50

16. Furuta $Y$, Piston DW and Hogan BL (1997) Bone morphogenetic proteins (BMPs) as regulators of dorsal forebrain development. Development 124: 2203-2212

17. Liem KFJ, Tremml G and Jessell TM (1997) A role for the roof plate and its resident TGF $\beta$-related proteins in neuronal patterning in the dorsal spinal cord. Cell 91: 127-138

18. Nguyen VH, Schmid B, Trout J, Connors SA, Ekker M and Mullins MC (1998) Ventral and lateral regions of the zebrafish gastrula, including the neural crest progenitors, are established by a bmp2b/swirl pathway of genes. Dev. Biol. 199: 93-110

19. Nguyen VH, Trout J, Connors SA, Andermann P, Weinberg E and Mullins MC (2000) Dorsal and intermediate neuronal cell types of the spinal cord are established by a BMP signaling pathway. Development 127: 1209-1220

20. Barth KA, Kishimoto Y, Rohr KB, Seydler C, Schulte-Merker S and Wilson SW (1999) Bmp activity establishes a gradient of positional information throughout the entire neural plate. Development 126: 4977-4987

21. Graham A, Koentges G and Lumsden A (1996) Neural crest apoptosis and the establishment of craniofacial pattern: an honorable death. Mol. Cell Neurosci. 8: $76-83$

22. Li W, Cogswell CA and LoTurco JJ (1998) Neuronal differentiation of precursors in the neocortical ventricular zone is triggered by BMP. J. Neurosci. 18: 8853-8862

23. Mehler MF, Mabie PC, Zhu G, Gokhan S and Kessler JA (2000) Developmental changes in progenitor cell responsiveness to bone morphogenetic proteins differentially modulate progressive CNS lineage fate. Dev. Neurosci. 22: $74-85$

24. Gross RE, Mehler MF, Mabie PC, Zang Z, Santschi L and Kessler JA (1996) Bone morphogenetic proteins promote astroglial lineage commitment by mammalian subventricular zone progenitor cells. Neuron 17: 595-606

25. Megason SG and McMahon AP (2002) A mitogen gradient of dorsal midline Wnts organizes growth in the CNS. Development 129: 2087-2098

26. Graham A, Francis WP, Brickell P and Lumsden A (1994) The signalling molecule BMP4 mediates apoptosis in the rhombencephalic neural crest. Nature 372: 684-686

27. Weil M, Jacobson MD and Raff MC (1998) Are caspases involved in the death of cells with a transcriptionally inactive nucleus? Sperm and chicken erythrocytes. J. Cell Sci. 111: 2707-2715

28. Iemura S-I, Yamamoto TS, Takagi C, Uchiyama U, Natsume T, Shimasaki S, Sugino $\mathrm{H}$ and Ueno N (1998) Direct binding of follistatin to a complex of bone-morphogenetic protein and its receptor inhibits ventral and epidermal cell fates in early Xenopus embryo. Proc. Natl. Acad. Sci. USA 95: 9337-9342

29. Zimmerman LB, De Jesus-Escobar JM and Harland RM (1996) Spemann organizer signal noggin binds and inactivates bone morphogenetic protein 4 . Cell 86: 599-606

30. McMahon JA, Takada S, Zimmerman LB, Fan CM, Harland RM and McMahon AP (1998) Noggin-mediated antagonism of BMP signaling is required for 
growth and patterning of the neural tube and somite. Genes Dev. 12 1438-1452

31. Faure S, de Santa Barbara P, Roberts DJ and Whitman M (2002) Endogenous patterns of BMP signaling during early chick development. Dev. Biol. 244: 44-65

32. Dewulf N, Verschueren K, Lonnoy O, Moren A, Grimsby S, Vande SK Miyazono K, Huylebroeck D and ten Dijke P (1995) Distinct spatial and temporal expression patterns of two type I receptors for bone morphogenetic proteins during mouse embryogenesis. Endocrinology 136: 2652-2663

33. Zhang D, Mehler MF, Song Q and Kessler JA (1998) Development of bone morphogenetic protein receptors in the nervous system and possible roles in regulating trkC expression. J. Neurosci. 18: 3314-3326
34. Panchision DM, Pickel JM, Studer L, Lee SH, Turner PA, Hazel TG and McKay RDG (2001) Sequential actions of BMP receptors control neural precursor cell production and fate. Genes Dev. 15: 2094-2110

35. Hamburger $\mathrm{V}$ and Hamilton $\mathrm{HL}$ (1951) A series of normal stages in the development of the chick embryo. J. Morphol. 88: 49-91

36. Cohn MJ, Izpisua-Belmonte JC, Abud H, Heath JK and Tickle C (1995) Fibroblast growth factors induce additional limb development from the flank of chick embryos. Cell 80: 739-746

37. Smith WC and Harland RM (1992) Expression cloning of noggin, a new dorsalizing factor localized to the Spemann organizer in Xenopus embryos. Cell 70: $829-840$

Supplementary information accompanies this paper on the Cell Death and Differentiation website: http:// www.nature.com/cdd 